\title{
Learning by Doing: \\ Employer Expectations of Planning Studio Education
}

\section{To cite this Article}

Dorina Pojani, Laurel Johnson, Sébastien Darchen \& Katie Yang (2016): Learning by Doing: Employer Expectations of Planning Studio Education, Urban Policy and Research, DOI: 10.1080/08111146.2016.1221814.

\section{To link to this Article}

\section{http://dx.doi.org/10.1080/08111146.2016.1221814}

\section{Acknowledgment}

This is an Author's Original Manuscript of an article whose final and definitive form, the Version of Record, has been published in Urban Policy and Research, 2016, copyright Routledge, available online at: http://www.tandfonline.com/doi/full/10.1080/08111146.2016.1221814 


\title{
LEARNING BY DOING:
}

\section{Employer Expectations of Planning Studio Education}

\begin{abstract}
Planning education is often criticized for being "too theoretical" and subsequently producing graduates who lack the requisite technical skills for the job market-who, in other words, are not "work ready." It is assumed that employers will prefer graduates with technical and procedural know-how. This article reports on an employer workshop to evaluate the urban planning studio courses at the University of Queensland in Australia. The results were surprising. The attending employers agreed that procedural planning skills can be learned "on the job" while the university environment is an opportunity to develop critical and spatial thinking.
\end{abstract}

\section{Introduction}

A distinct pedagogical tool, the studio is a mainstay of planning programs in many universities. The studio environment provides students with a quasi-real-world situation, which is not offered by traditional courses with a lecture or seminar format. Studio teaching presumes "learning by doing." The students work under guidance (generally in teams) to prepare plans and designs for selected sites. In this manner, students "get to do" planning. Studio courses aim to bridge the gap between theory and practice. Most use experiential learning techniques to apply the theories of spatial planning and design to "real world" scenarios, thereby positioning the development of practice skills in a theoretical frame (Németh and Long 2012; Balassiano 2011).

Experiential learning is defined as follows: "a purposeful process of engaged, active learning in which the student constructs knowledge, skills or values by means of direct experiences in authentic, "real world" contexts. It puts the learner in the center of their learnings" (Australian Government 2014, p. 29). In applied fields such as urban planning, experiential learning is an essential education technique. This is because experiential learning is "a means to broaden students' learning experiences by placing them in a new context for learning, in and from the world outside the university" within their professional field. Students of applied disciplines such as urban planning need to engage in education that promotes dialectic transfer of theory into practice and vice versa (Baldwin and Rosier 2015). Experiential learning is aligned with 
this learning outcome as it incorporates a variety of activities that encourage student engagement with applied learning tasks. A central feature of planning education, planning studio pedagogy includes a number of experiential learning activities, such as site visits, case study analysis and problem-solving, and guest lectures. It also has attributes related to "work readiness": for example, the application of planning procedures to the field; the development of teamwork skills; and the provision of a "professional socializing experience" (Thomas and Hollander 2010).

Due to their participatory and collaborative nature, studio courses are not generally conducted online. They require class attendance and active participation and engagement with the project and the team (see Wenger 2000 on "communities of practice" and "social learning systems"). Students and instructors work together on a professional level to prepare designs, plans, implementation strategies, and feasibility assessments for selected areas of the city (Fisher 2004). Typically, studios focus on planning-related tasks or issues that involve creative thinking and critical analysis to produce a practical solution to a planning site. Studios are also meant to equip planners with skills such as project management, teamwork, and leadership. More than an opportunity for theoretical reflection, they offer a context for practical innovation (Higgins et al. 2009). Through effective studios, future planners can learn to deal with complex contemporary issues (Vella et al. 2014).

But, what constitutes an effective planning studio in the contemporary world? The current challenges facing cities in Australia and globally, including extreme car dependence, urban sprawl, and climate change, require innovative thinking in order to be tackled. Are students "thinking outside the box" in studio courses or are they applying conventional solutions to common challenges? At the same time, planning students expect to be "work-ready" at graduation. Can, should, and do planning studio courses develop the skills that employers are wanting in a planning graduate?

University education, in general, is often criticized for being "too theoretical" and subsequently producing graduates who lack the requisite technical skills for the job market. In applied disciplines such as urban planning, this pressure is constant. It creates a tension between the teaching of technical and procedural skills such as development assessment and equipping graduates with critical and spatial thinking capacities. It is assumed that employers will prefer graduates with technical and procedural know-how. 
This study explored this tension through a workshop with planning employers, conducted at the University of Queensland (UQ) in Brisbane, Australia. The purpose of the workshop was twofold: (1) Examine what constitutes sound planning studio pedagogy in relation to what planning employers expect from planning graduates when the latter enter the workforce. Are students being trained to meet the demands of the current job market? (2) Examine whether planning academia is at the forefront of innovation. Can planning practitioners learn from student ideas? Are "innovative planners" in demand in the Australian, and more broadly, the global context? Are planning studios more effective than traditional planning courses in fostering innovation and critical thinking among students? Given that the objectives and learning outcomes of the two studio courses in UQ's planning program are rather standard within Australia (see Németh and Long 2012), the workshop findings are likely to be generalizable to other contexts in the country, and perhaps farther afield.

The article is organized in the following manner. The first part sets forth the institutional and theoretical context of this study. The second part presents the workshop methodology. And the third part discusses the findings, which can help studio instructors in urban planning programs enhance the learning outcomes and the employability of their students, as well as engage planning academics with the industry.

\section{Institutional and Theoretical Context of Study: Learning Outcomes of Planning Studio Courses}

Urban planning education is offered in 24 of Australia's universities. Together, Australian universities deliver over 50 accredited urban planning programs. UQ is one of the oldest, largest, and highest ranking universities in Australia. It is part of the Group of Eight (Go8) - a coalition of research-intensive Australian universities. UQ provides two accredited urban planning degrees (undergraduate and postgraduate): a four-year Bachelor of Regional and Town Planning (BRTP) and a two-year Master of Urban and Regional Planning (MURP). The planning programs are embedded in the School of Geography, Planning and Environmental Management, and therefore have a stronger spatial and social science rather than design inclination.

Both UQ's planning programs strive to maintain a strong relationship with planning professionals. This is important to the accreditation, the credibility, and the quality of the programs. Many planning professionals work with the university's academics and the students to enhance the quality of the programs. One way that planning professionals are engaged is in 
the evaluation of course outputs through the grading of research projects and, more recently, in the workshop on which this article reports. The workshop is the first time that the university has brought planning professionals together in a facilitated review process.

The workshop evaluated the recent products of two planning studios in the BRTP - one in the second and one in the third year. The studio teachers are academics with former experience in planning practice. Based on student evaluations over the past three years, both courses are among the top ranked among a total of 15 courses. This demonstrates that students appreciate studio courses more than courses which have a lecture or seminar format. The planning students have preliminary skills when they commence the studios such as site and precinct analysis, design assessment and graphics, research and writing, and team work. The studio courses extend and consolidate these skills and apply them in plan making projects at selected sites in the city.

In the second-year studio students learn how to: develop a vision, design desired environmental outcomes for a local area that express its preferred future character; identify and develop planning instruments and implementation strategies which are used to deliver the vision; design desired environmental outcomes and control the type, intensity and physical form of land use; and engage with local resident leaders to understand the role of community values and issues in local planning. The project scale is local. In the third-year studio, students learn how to: apply urban regeneration theory to a specific location; audit a site; develop a conceptual development plan; develop a design proposal that is commercially viable; cost a development; and assess project feasibility. The project scale is still local - but smaller and more focused than in the earlier studio. Both studio courses include site visits to assess the strengths and weaknesses of an urban area. An urban design evaluation is prepared after site visits.

As seen, the teaching and learning style of these studios is by no means "high tech": it relies on "traditional" techniques. For example, digital serious gaming has not been employed. While the potential of web-based technology to enhance the learning activities in the studios is acknowledged, that was not the focus of the course review. However, the instructors have incorporated novel elements in recent years, which enhance interaction and real world application. In the second year studio, students are briefed by a panel of key community representatives at a community location in the project area. This briefing occurs at the outset of the project, in order to introduce students to the concept of "community values" as guidance for local planning. The community values and specific issues raised by the community are referenced throughout the semester and are expected to be reflected in the final project. This 
ensures a process whereby planning students cannot approach their project with preconceived ideas - or ideas borrowed from other places and courses. The issues emerge from community engagement. The students are also asked to write the development codes, which will both facilitate and control the implementation of their proposals and designs. (Development codes are the technical regulations by which development proposals are assessed in the State of Queensland.) Another teaching novelty occurs in the third year course. In this studio, students are taught how to assess the financial feasibility of their proposals in order to understand the market processes and their role in project implementation. They learn how to integrate the planning and commercial viability aspects of urban development.

The learning outcomes of both studio courses are developed in accordance with the eight principles of "experiential learning" in planning education, set forth by the University of the Sunshine Coast in Australia. Experiential learning is defined as a purposeful process of engaged, active learning in which the student constructs knowledge, skills, or values by drawing on direct or concrete experiences in authentic, real world contexts, through observation and reflection, to integrate abstract theory and concepts, which in turn are tested in new situations (Kolb and Kolb 2005). In the ambit of planning education, experiential learning abides by the following eight principles: purposeful; student-centered; theory-practice dialectic (i.e., apply theory to practice and vice versa); "real world" context; guided practice; reflection on learning; evaluation of learning; and community-university partnership (Baldwin and Rosier 2015).

The learning outcomes of studio courses are also developed in accordance with the guidelines of the Planning Institute of Australia (PIA). In Australia, a planning program is accredited when the learning content attains the PIA approval. To be accredited, a university must demonstrate that its urban planning program addresses a number of content areas and competencies. The idea is that the universities will produce graduates who are capable of operating in the Australian planning environment. The PIA's general capabilities and competencies (referred to as "graduate attributes") include critical analysis, spatial thinking and application, communication and teamwork, and work readiness among others (PIA 2015).

The definitions of these attributes follow below. They were used in the workshop in order to structure the discussion and evaluate whether studio products demonstrate that the students have acquired these graduate attributes. 
Critical analysis is the ability to develop and evaluate arguments. Spatial thinking and application, which includes design skills, is the capability to make meaningful new connections between apparently challenging, contradictory or unlikely elements, think strategically and apply planning concepts and knowledge in a range of spatial settings. Communication and teamwork, in combination, constitute critical elements of negotiation. Communication is defined as the ability to write and speak with clarity, cohesion, logic, structure, relevance, accuracy, and precision of expression in a range of contexts. A key element of communication is the effective use of voice, body-language, word choice, graphics, and presentation technology, across a range of media that is appropriate to the knowledge base and cultural background of the audience. Recent graduates are expected to operate in a manner that recognizes cultural diversity, the need for equity in outcomes. They must have knowledge on professional ethics, and strive to maintain high ethical standards. Teamwork is the ability to work as a team member, with commitment to shared goals, team processes and appropriate interpersonal skills, including respect, reliability, mutual supportiveness, and time management. Work-ready planning graduates are expected to work in diverse employment situations requiring the application of both theory and technical skills (PIA 2015).

Curiously, innovation, vision, and creativity are not listed among PIA's graduate attributes. However, given the nature of studio courses, which borrow elements from architecture studios, the desirability of an "innovative vision" and "creativity" among planning graduates was also discussed in the workshop. The authors defined these terms, based on the Australian Institute of Architects policies on university education in architecture, as "an understanding of the tangible and intangible channels to urban design creativity; an ability to engage imagination and to think creatively; an ability to reconcile divergent factors and integrate domains of knowledge in the creation of a design solution" (AIA 2009).

While the above are ideal attributes, academic planners recognize that, in a studio course complex urban problems are simplified in order to make the teaching experience more manageable within a limited timeframe (usually one semester or quarter). But, the more manageable the studio experience becomes, the less similar it is to actual planning practice. Necessarily, the university setting imposes some limits to the approaches taken to solve “wicked problems" (Balassiano 2011; Vella et al. 2014). 


\section{Methodology}

The workshop took place in October 2015 and lasted between 2.5 and 3 hours. About 70 invitations were sent to planning practitioners from a range of sectors including the state and local governments, the Planning Institute of Australia, and planning consultancy firms in Brisbane and surroundings. These practitioners are employers who were strategically selected as they are likely to hire the planning program graduates of the University of Queensland. Several participants came from the Professional Advisory Board - a board retained by the planning programs at UQ to complement and extend the PIA accreditation process. The Board guides the learning programs in both degrees; however, board members are not involved in teaching at UQ (BRTP and MURP).

A dozen people attended the workshop (five women and seven men), in addition to four moderators (the present authors). This number of participants is deemed adequate for qualitative research of this nature, which targets experts rather than the population at large (Baker and Edwards 2012). Also, the response rate (17\%) is deemed adequate considering that participating in the workshop required of the volunteers a time commitment of several hours (after the workday) and travel to the University of Queensland campus. Overall, the expertise of the participants varied. For example, strategic planning, statutory planning, urban design, architecture, and community organization skills were represented in the group. Most workshop participants had work experience in other Australian cities in addition to Brisbane and some had international experience.

The workshop employed a modified focus group format. The discussion was qualitative and guided through questions posed by the moderators. The PIA graduate attributes, mentioned above, were also discussed as they apply to UQ's studio courses. Overall, the workshop was low-tech and relatively low-cost (the main expense being a catered dinner for participants), and could be easily replicated elsewhere.

The session was in two parts. In the first part, the participants evaluated planning skills and competencies that they considered important for planning graduates - based on the PIA graduate attributes, discussed above. Workshop participants were invited to prioritize the PIA graduate attributes and identify any other attributes that they felt were important for planning graduates. This process of prioritisation was achieved through a short survey of participants. Each participant nominated their priority graduate attributes from the list. The whole group then discussed and agreed upon a set of priority graduate attributes based on their individual 
responses. One of the moderators noted simultaneously the main points raised by the participants, which were displayed on a screen and used to elicit further discussion.

In the second part of the session, participants evaluated the content and the graphic quality of studio projects (keeping in mind the earlier survey questions as basic evaluation criteria). In total, six student projects were selected for evaluation in the workshop. They included the best projects (i.e., those which received the highest grade) in each of the two studios in the past three years. The projects were presented in the form of a printed booklet in A3 format, which contained both texts and graphics. They had been prepared by student teams (3-5 people) rather than individual students. There were six project reports with different content. The reports were each for different areas of the city and at different scales (three projects were precinct-wide plans and three were site plans). Other differences were that half included feasibility analysis and the other half included development codes. Both had site analysis and design elements.

A "speed dating" style evaluation method was followed. The projects were displayed on six tables laid out in a circle. Small groups of participants (of three persons each) spent a short amount of time (10 minutes) reviewing each project and writing related notes on a board. After the time was up, participants were asked to rotate clockwise to the next table. This process was repeated until all the groups had reviewed all the projects. The session concluded with a guided discussion of the quality of studio products.

The workshop proceedings were voice recorded and later transcribed and coded. The notes produced by the participants and the moderators were also transcribed and coded. The analysis of the notes and transcripts was manual and followed a standard iterative process commonly used with qualitative data.

\section{Findings}

In the authors' interpretation, three themes recurred in the workshop: (1) strategic thinking vs. technical skills; (2) design skills and spatial thinking; and (3) negotiation skills vs. creative and innovative vision. These are discussed in turn.

\section{Strategic Thinking vs. Technical Skills}

Most participants are in agreement that, for planning graduates an "inquiring mind" is much more desirable than purely technical skills, and studio courses must focus on strengthening strategic thinking. Technical skills in this context refers to contextual analysis, feasibility assessment, development code, and plan drafting. After completing a studio course, students 
should be able to identify and solve problems pragmatically. Most importantly, they need to understand the role of planners in the development process spectrum and their relationship with other professionals, including developers, architects, contractors, community organizers, environmental managers, economists, and others. Given the diversity of planning projects, studio courses can give students' a "taste" of the potential role of their peers from other professional fields, and possibly acquire some of their skills in a generic way. Thus students can realize the limits of planners' expertise and the overlaps between this profession and others.

Several workshop participants note that often there is a disjoint of young graduates' understanding of the planning process. They struggle with questions such as: Where do planners fit in "planning"? What brings a long-term project together? What is the ultimate goal of planning? How is urban space produced and governed? This lack of comprehensive understanding sometimes affects longtime practicing planners too, as they might become pigeonholed in specialties. If and when planners come to realize the answers to these questions (preferably as early as during studio courses), they can play a positive role in the management of cities.

Procedural skills - i.e., being equipped to assess a development application, and the like - are considered of secondary importance in studio teaching. Most workshop participants took the position that, this type of technical, procedural learning can take place quickly on the job, provided that graduates have mastered planning and urban theory while at university, and have become sophisticated thinkers.

\section{Design Skills and Spatial Thinking}

Workshop participants note that, often planning graduates - as opposed to architecture graduates - are "frightened of design." Many lack the competency to envision the character of a site. Some studio projects are criticized for lacking contextualization, i.e., a "sense of place." For example, one project proposed to create a subtropical design in an urban park - Brisbane's climate being subtropical - but this was poorly conveyed by the design. In others, questionable solutions for issues such as parking or car access or the location of bus stops, or an overly rigid land-use design are noted. At the same time, designs that are interesting or even somewhat adventurous are praised. Practitioners suggest that students prepare an album, in which to collect sketches prepared during the semester, in order to trace the evolution of their spatial thinking and discern the different design and planning options that have influenced and inspired the end product. 
Also, "mere" graphic representation is considered crucial in planning documents. Participants note the negative impact (in terms of a perception of professionalism) of seemingly minor inaccuracies such as inconsistent fonts, text sizes, or layout, wordiness, imbalance between the amount of text and images, poor legibility or blurriness or images, clumsiness, typing errors or imprecise language, and lack of an executive summary. At the same time, participants are impressed by studio projects that have a high graphic standard and thus convey a sophisticated communication capability.

Practitioners stress that design skills take time to build, and the only guaranteed method to acquire them while studying is through hands-on projects in studio courses. Simply teaching students how to use computer-aided design software in seminar courses has little value in shaping spatial thinking. By spatial thinking, practitioners mean, for example, an understanding of how a street and a building relate to each other and how that relationship can be improved; how do vegetation and seating impact the pedestrian experience in public space; how does a tall building affect the public realm, and whether its effect can be modified by creating a podium or stepping back upper floors, and so on. As such, design must be more fully incorporated in the studio curriculum. One successful method is to combine architecture and planning students within the same studio course so that they can learn and support each other.

Finally, an understanding of Geographic Information Systems (GIS) is important for recent graduates, but not only in terms of design (mapping) aspects. Data management and interpretation skills are crucial too. Most importantly - and this connects to strategic thinking - planners must be able to discern what type of data must be collected for a project, and how it should be graphically represented, in order to brief GIS analysts.

\section{Negotiators vs. Visionaries}

Most workshop participants suggest that an ability for negotiation and communication is more important for planning graduates than visionary talent. Studio courses must focus on sharpening students' skills in "community engagement", "running a meeting," "writing a report," and "giving an oral presentation" - as well as graphically representing space, as discussed. This approach, focused on planning process rather than outcome, might seem to reinforce the status quo.

However, participants take the position that, in the contemporary world, planners have become facilitators rather than visionaries. Their role is to bring together and coordinate the different parties that are involved in the process, including developers, engineers, architects, landscape 
designers, economists, environmental managers, and most importantly community members. While planners can help mold the concepts of these stakeholders, they can no longer dominate the process with their own visions - as in the "Golden Era" of planning. The important role of community consultation is emphasized in the studio courses with engagement at the outset to scope the students' plans and designs in the community interest.

Some studio projects are criticized for not clearly indicating whose vision is represented and supported. Practitioners note that, some planning students do not seem to fully understand that any design produced in a studio, far from being the ultimate solution, is just one potential scenario of how space could be arranged given certain site constraints.

While studio instructors (the present authors) have noted a desire to be innovative among students in the studios at UQ, they have also noted the hesitation and inhibition of many students to engage with new ideas and new ways of thinking. Those team products that teachers (and employers participating in the workshop) agreed demonstrated innovation were the plans that were prepared by a team of combined architecture and planning students.

\section{Conclusion}

Inviting planning practitioners to evaluate studio products proved invaluable. Through the process, the practitioners identified the attributes of a "work ready" urban planner. Spatial thinking, generating design solutions, critical analysis, and negotiation and communication skills were the graduate attributes that practitioners (employers) prioritized. Practitioners felt that other skills, such as procedural techniques (e.g., evaluation of development applications) will be learned on the job with the mentoring of more experienced colleagues. Visionary talent is less important for planners than it is for architects.

This study demonstrates that planning studio courses are not only popular with students (based on student evaluations), but they are also validated by planning practitioners as an essential teaching strategy. The review of the content and products of the studio courses at the University of Queensland resulted in general praise from the planning practitioners. While the reviewers endorsed those plans that displayed adventurous and innovative design, they were most impressed by the plans that demonstrated the effective communication of coherent ideas. The practitioners recommended an extension of teaching content to include graphic and written communication skills development. These suggested areas for course improvement reflect an expectation that the graduate planner in Australia will be an effective communicator and not necessarily an innovative designer. This is a factor of the communicative nature of the 
contemporary planning practice (see Allmendinger and Tewdwr-Jones 2002). An effectual planner is facilitative. He or she accommodates the views and values of multiple stakeholders in designs and plans.

Given that most workshop participants had work experience in other cities in Australia in addition to Brisbane, the results are certainly applicable to other contexts within the country. However, in terms of applicability to an international context, it must be noted that the findings are context-dependent to some degree. Clearly, local variables in Australia, such as the nature of the urban environment, the local culture, the system of governance, the consumption patterns, and the economic cycles will affect the way in which planning operates. While from a purely academic perspective findings that are generalizable at an international level are more desirable, planning practitioners (as well as students that are ready to join planning practice) are likely to find more interesting the perceptions of their peers at national, regional, or local level. A main recommendation for planning programs internationally is to periodically organize these types of workshops with local employers to evaluate course content and products, in order to ensure that studio learning meets the market expectations of graduate capabilities.

\section{References}

Allmendinger, Philip and Mark Tewdwr-Jones. 2002. "The Communicative Turn in Urban Planning: Unravelling Paradigmatic, Imperialistic and Moralistic Dimensions.” Space and Polity 6(1):5-24.

Australian Institute of Architects. 2009. "Policy on Tertiary Education of Architects Standards for Programs in Architecture.” Report. Available at: http://www.architecture.com.au/docs/default-source/schools-education/standards-forprograms-in-architecture.pdf?sfvrsn=0 Last retrieved on 10 January 2016.

Baker, Sarah, and Rosalind Edwards. 2012. "How Many Qualitative Interviews Is Enough?

Expert Voices and Early Career Reflections on Sampling and Cases in Qualitative Research.” Report, ESRC National Centre for Research Methods, University of Southampton. Balassiano, Katia. 2011. "Tackling Wicked Problems in Planning Studio Courses". Journal of Planning Education and Research 31(4):449-460.

Baldwin, Claudia and Johanna Rosier. 2015. "Growing Future Planners: A Framework for Integrating Experiential Learning into Tertiary Planning Programs.” Journal of Planning 
Education and Research DOI. Last retrieved March 2016.Fisher, Thomas. 2004. "The Past and Future of Studio Culture.” ArchVoices 15 October.

Higgins, Marilyn, Elizabeth Aitken-Rose, and Jennifer Dixon. 2009. "The Pedagogy of the Planning Studio: A View from Down Under.” Journal of Education in the Built Environment (4)1:8-30.

Kolb, Alice and David Kolb. 2005. "Learning Styles and Learning Spaces: Enhancing Experiential Learning in Higher Education.” Academy of Management Learning Education 4(2):193-212.

Németh, Jeremy and Judith Long. 2012. “Assessing Learning Outcomes in U.S. Planning Studio Courses.” Journal of Planning Education and Research 32, 476-490.

Planning Institute of Australia. 2015. "Accreditation Policy for the Recognition of Australian Planning Qualifications.” Report. Available at: https://www.planning.org.au/documents/item/48 Last retrieved on 10 January 2015.

Thomas, David and Justin B. Hollander. 2010. "The City at Play: Second Life and the Virtual Urban Studio." Learning Media and Technology (35)2:227-242.

Vella, Karen, Natalie Osborne, Severine Mayere, and Douglas Baker. 2014. "Studio Teaching in Australian Planning Curriculum.” Paper presented at Australia \& New Zealand Association of Planning Schools Conference (ANZAPS), 3-5 October, Massey University, Palmerston North, New Zealand.

Wenger, Etienne. 2000. "Communities of Practice and Social Learning Systems.” Organization 7:225. 